\title{
Implementation of a Near-Peer Teaching Model in Pharmacy Education: Experiences and Challenges
}

Christine Leong, Marisa Battistella, and Zubin Austin

\section{INTRODUCTION}

$\mathrm{T}$ here is an increasing demand for high-quality experiential placements for pharmacy students. ${ }^{1}$ As a result, pharmacy schools across Canada are confronted with the need to find innovative ways to expand experiential educational rotations.

Near-peer teaching is one model with the potential to address this issue. Near-peer teaching involves the provision of learning support to junior students by their senior peers. ${ }^{2}$ This teaching methodology, which is common in many medical education programs, ${ }^{1,3}$ is thought to allow pharmacy students a unique learning environment for integrating pharmacy knowledge into pharmacy practice. ${ }^{4,5}$ It gives the student access to an additional potential learning environment without unduly increasing the preceptor's workload. ${ }^{5-7}$

Although peer teaching has been well established in many health care communities, this approach has not been widely adopted in pharmacy education. ${ }^{6-8}$ This paper describes the experiences and challenges of this teaching model in pharmacy education within a specialized hospital setting.

\section{DESCRIPTION OF EDUCATIONAL SETTING}

\section{Participants and Setting}

Near-peer teaching was carried out within a group of 4 pharmacy students in a hemodialysis unit in a teaching hospital. The unit provides care to 300 hemodialysis patients in a multidisciplinary environment. Each patient undergoes dialysis for $4 \mathrm{~h}$ at least 3 times per week.

The primary participants involved in this teaching model were the attending pharmacist, a post-baccalaureate Doctor of Pharmacy (PharmD) student with 3 years of previous hospital experience, a pharmacy resident who had been with the institution for about 6 months, a third-year pharmacy cooperative (co-op) student, and a fourth-year pharmacy SPEP (Structured Practical Experience Program) student. The
PharmD student and the resident were considered senior students, and the co-op and SPEP students were considered junior students. All students were participating in the rotation for academic credit, as organized by their respective educational programs.

The attending pharmacist had worked as a clinical pharmacist in the hemodialysis unit for 8.5 years and had previous experience functioning as a preceptor for multiple pharmacy students (usually 2 or 3 ) at one time. All of the students had had minimal exposure to the nephrology setting and various degrees of hospital experience before starting the rotation, on January 3, 2012 (Table 1).

\section{Rotation and Teaching Environment}

The rotation was a clinical rotation involving direct patient-care experience for all students, as well as teachingrelated experience for the senior students. During the first 2 days of the rotation, the attending pharmacist provided orientation for the pharmacy students. The students had a guided tour of the clinic area and were introduced to staff members. Learning objectives and expectations in the areas of patient care, clinical knowledge, and pharmaceutical process development were also individually reviewed between the attending pharmacist and each pharmacy student. Teaching expectations were discussed with the PharmD student and the resident. All students were made aware that the amount and quality of their participation in teaching and peer-learning would have no impact on their evaluation for the rotation. None of the students received any instruction on appropriate and effective teaching methods before or during the rotation.

The rotation consisted of a number of scheduled educational activities in which all students had the opportunity to participate (Box 1). In addition to these activities, each student was also responsible for providing pharmaceutical care for at least 8 assigned patients throughout the course of the rotation. The number of patients assigned was based on the student's 
This single copy is for your personal, non-commercial use only.

For permission to reprint multiple copies or to order presentation-ready copies for distribution, contact CJHP at cjhpedit@cshp.ca

Table 1. Description of Educational and Experiential Background of the 4 Pharmacy Students Involved in Near-Peer Teaching Model

\begin{tabular}{|c|c|c|c|c|}
\hline Student & Program Description & $\begin{array}{l}\text { Length of } \\
\text { Rotation }\end{array}$ & $\begin{array}{l}\text { Previous Hospital } \\
\text { Experience }\end{array}$ & $\begin{array}{l}\text { Nephrology } \\
\text { Experience }\end{array}$ \\
\hline PharmD & $\begin{array}{l}\text { - 2-year post-baccalaureate program: } 1 \text { year academic training, } \\
\text { eleven 4-week practical rotations } \\
\text { - Evaluation of evidence and application to clinical practice }\end{array}$ & 4 weeks & $\begin{array}{c}\text { Yes } \\
\text { (3 years) }\end{array}$ & 1 month \\
\hline$\overline{\text { Resident* }}$ & $\begin{array}{l}\text { - 1-year advanced hospital training program } \\
\text { - Practical hospital experience in patient and non-patient } \\
\text { care areas }\end{array}$ & 4 weeks & $\begin{array}{l}\text { Yes } \\
(6 \text { months as } \\
\text { a resident) }\end{array}$ & None \\
\hline Co-op student* & $\begin{array}{l}\text { - 4-year undergraduate program: } 4 \text { months of academic } \\
\text { training alternating with } 4 \text { months of practical experience }\end{array}$ & 4 months & $\begin{array}{l}\text { Yes } \\
\text { (4 months as a } \\
\text { co-op student) }\end{array}$ & None \\
\hline$\overline{\text { SPEP }}$ & $\begin{array}{l}\text { - 4-year undergraduate program: } 3 \text { years of academic training, } \\
\text { with final year including } 2 \text { months of academic training } \\
\text { followed by two 4-week hospital rotations and two 4-week } \\
\text { community rotations }\end{array}$ & 4 weeks & No & None \\
\hline
\end{tabular}

SPEP = structured practical experience program.

*The resident and the co-op student were receiving a stipend as organized by their respective programs. The other students were not receiving any form of remuneration.

program requirements and the experience of the attending pharmacist, who had served as a preceptor for pharmacy students in the past.

The pharmacist led 2 types of group teaching sessions for the pharmacy students: therapeutic discussions and patient updates. For the therapeutic discussions, students were provided with readings on selected topics in nephrology and were expected to prepare for detailed group discussion of these readings. For the patient updates, the students regularly met as a group to provide updates on their assigned patients, with the opportunity to ask questions regarding appropriate care. Each of these activities occurred at least 3 times a week, with each session lasting 1 to $3 \mathrm{~h}$, which gave the students the opportunity to work up assigned patients, to review assigned readings before therapeutic talks, and to attend scheduled educational activities conducted by other members of the health care staff.

In this teaching model, the resident and PharmD student also performed teaching activities with the junior students. The major activity was assisting in the complete work-up of the junior students' patients and conducting patient interviews (Box 2). For these teaching activities, the attending pharmacist provided minimal direction, to allow the senior students the flexibility to impart knowledge and skills that they felt most comfortable sharing. No attempt was made to assess the quantity or quality of the peer teaching performed by any of the participants.

The attending pharmacist was responsible for the final evaluation of the students' overall performance. Evaluation forms were provided, and required, by the academic institution of each student. Assessment of each student was largely based on observed interactions between the student and the pharmacist, patients, health care staff, and other pharmacy students. Feedback from health care staff and fellow pharmacy students was invited but not required.
Box 1. Educational Activities Available to All 4 Students in Near-Peer Teaching Model

Nephrology teaching rounds (every Thursday at noon and Friday morning)

Nephrology journal club (every Tuesday at noon)

Interprofessional patient rounds (variable; every Tuesday

morning)

Therapeutic discussions with the pharmacist (variable)

Patient discussions with the pharmacist (variable)

Educational session with the nurse or dietitian (variable)

Pharmacy department presentations (variable)

Box 2. Examples of Senior Students' Teaching Activities with Junior Students

\section{Resident}

Chart review

Best possible medical history, medication reconciliation

Patient interview

Patient work-up and therapeutic thought process

Documentation

PharmD student

Appropriateness of drug therapy

Important studies supporting or refuting an intervention used in practice

This project was approved by the University Health Network Research Ethics Board. All participants were informed of the presence of the observer and the nature of the information to be collected. All students expressed their interest in participating in this teaching model. 


\section{DOCUMENTATION OF STUDENT EXPERIENCES}

A nonparticipant observer, also a pharmacist, was present for 4-6 h each day to observe the interactions between pharmacy students learning in a near-peer teaching environment. The observer made no attempt to assess the accuracy or quality of teaching by any of the participants. Qualitative information, in the form of field notes and semistructured interviews, was collected over a 3-week period concerning the experiences of pharmacy students participating in this teaching model. The methods used for collecting information were guided by ethnographic principles, which aim to describe the nature in which members of a group interact with one another and which have increasingly been recognized as a valuable strategy for studying the culture of learning that occurs in health care education. ${ }^{9-12}$ On a weekly basis, the observer consulted with an impartial advisor with expertise in the area of educational research for debriefing and assistance in interpreting the events of the previous days.

At the end of the observation period, common themes were identified and member validation was carried out, during which all participants were given the opportunity to review the documented information and confirm the interpretation and understanding of the findings.

\section{PROGRAM EXPERIENCE AND CHALLENGES}

Four recurring themes emerged with implementation of the near-peer teaching model in this setting: the importance of organization and time management, the recognition of a unique hierarchy among pharmacy students in this setting, the opportunity for cognitive congruence among the pharmacy students, and the emergence of culture learning within an interprofessional environment. The following sections describe the experiences and challenges observed among the participants in this teaching model.

\section{Theme 1: Organization and Time Management}

\section{Managing the Schedule}

Organization and effective planning appeared important for students to manage time spent attending educational activities, catching up on assigned readings, participating in teaching activities involving the senior and junior students, and providing care for their assigned patients. Being pressed for time was a particular concern in the first week of the rotation:

Resident (at week 1): "Scheduling-wise it is difficult because there are so many people to determine where they go and when."

However, despite the need to revisit the schedule periodically, it was felt that the attending pharmacist was well organized and that learning objectives were being met. Moreover, the pharmacist appreciated the help she was getting from the senior students:

Pharmacist (at week 2): "I like how the PharmD and resident have helped a lot with the teaching. I felt that has gone well. They helped go see patients and review cases."

\section{Repetition of Information}

Repetition of information tended to occur when more than one teacher was involved in reviewing a junior student's care plan for a single patient. For instance, the resident would walk through some of the learning activities with the junior students (e.g., medication reconciliation), whereas the PharmD student performed other activities (e.g., evaluating the appropriateness of therapy in more detail). Ultimately, this information was repeated again when the students reported their progress to the attending pharmacist. Repetition of information was also observed during interprofessional patient rounds:

Pharmacist (at week 2): "I think when you are rounding-when you're one-on-one-you can actually do more teaching on the side because things come up that you can explain. It's a little harder when there's 5 people."

\section{Theme 2: Perception of Roles and Structure of the Teaching Model}

\section{Role as Teacher}

The PharmD student and the resident often acted as co-teachers for the junior students. These senior students gave the junior students different perspectives on patient-related issues, while appearing to mutually respect each others' opinions, skill sets, and previous pharmacy experience. The PharmD student and the resident would frequently start sentences with expressions such as "Like [the resident] was saying..." or "I agree with [PharmD]'s comments about...." The PharmD student also began to distinguish herself through her teachings as being very knowledgeable clinically, whereas the resident imparted many skills related to performing a thorough and efficient patient review:

Co-op student (at week 3): "I feel like with [the resident] I developed more of my med histories with her. More so the patient interaction part of it I think I learned a lot more from her about that. I think with [the PharmD student] I learned more about the drugs and therapeutics part because for some reason I always tend to go to her and ask her questions."

This teaching model resulted in a hierarchical structure that took on a slightly different form in this setting than that expected in a medical education environment (Figure 1). ${ }^{13}$ 
Expected hierarchy

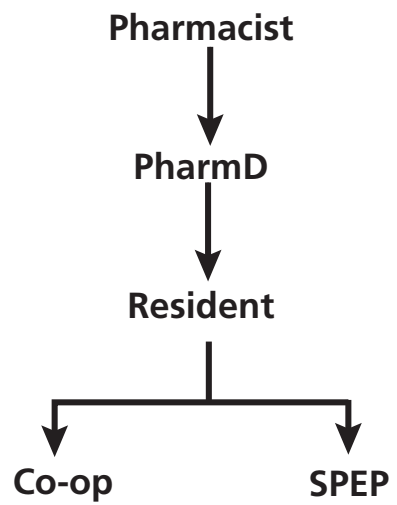

Structure that actually occurred

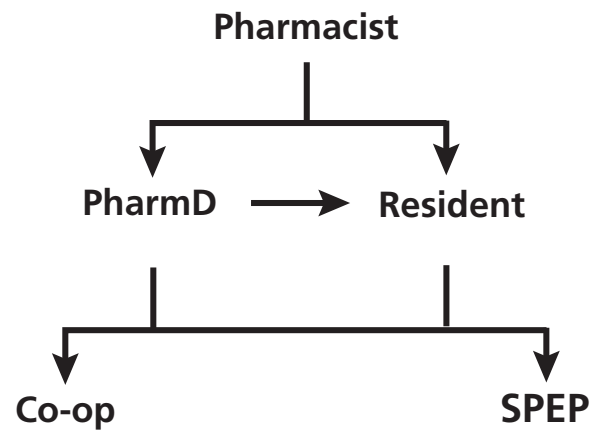

Figure 1. Expected and observed patterns of interaction between pharmacist and pharmacy students. SPEP $=$ Structured Practical Experience Program.

\section{Pattern of Participation During Group Discussions}

During group discussions and rounds in which all 4 students were present, the co-op and SPEP students were the least likely to respond to clinical questions prompted by the educator, regardless of who was serving as the educator (the clinical pharmacist, a nurse, a dietitian, or a physician). This finding may have implications in terms of the impact of this teaching model on opportunities to participate and contribute to clinical discussions, relative to a one-on-one teaching model between a pharmacist and a student.

One strategy that the attending pharmacist used during therapeutic discussions involved allowing the junior students the opportunity to answer the more fundamental questions first. These included questions related to pathophysiology, etiologies, and prevalences of various conditions in chronic kidney disease. Senior students were often asked direct questions related to evidence and the actions they would take in a specific clinical scenario. Time spent reviewing the more basic to the more advanced concepts appeared to maintain the interest of the entire group:

Pharmacist (at week 2): "I like when we discuss patients in a group because everybody brings something to the table. Because if it's just me and the student, it's just my experience. So I like it when the PharmD's there and the resident because they have different experiences as well."

\section{Theme 3: Opportunity for Cognitive Congruence}

Students learning in a near-peer teaching model share a similar knowledge base, which allows peer-teachers to use language that the junior students will understand. ${ }^{14,15}$ This con- cept is known as cognitive congruence. ${ }^{11}$ In this model, the junior students had more opportunities to discuss information with the senior students than with the pharmacist:

Co-op student (at week 3): "A good thing is that I had more than [the pharmacist] to ask questions to, which was definitely helpful. If I wasn't able to go to [the PharmD student or the resident], I think I would have found it much more difficult. I think so far it has worked well."

\section{Theme 4: Culture Learning and Integration into the Interprofessional Team}

\section{Legitimate Peripheral Participation}

During interprofessional rounds, the relationships among the attending physician, the nurse, and the pharmacist appeared clearly established. However, the pharmacy students, particularly the junior students, initially appeared slightly reserved, and integration within the team did not occur immediately. Instead, legitimate peripheral participation was evident during the first week of rounds.

Legitimate peripheral participation is a pattern of behaviour in which a newcomer is often observed at the periphery of a community. The person integrates more centrally as he or she becomes more familiar with the ways in which the new culture functions..$^{14}$ In social research, this phenomenon is referred to as culture learning, the process whereby newcomers acquire culturally relevant social knowledge and skills allowing them to thrive in their new society. ${ }^{16}$

Legitimate peripheral participation appeared to be a useful strategy for learning the way in which the medical culture worked in this model:

Co-op student (at week 2): "I'd say [this rotation has] helped me especially going on rounds with [the 
attending physicians]. I think I haven't really been exposed to that. I've done interprofessional workshops but it's all been with students so it's kind of nice to see how physicians interact with pharmacists. Seeing what they go to the pharmacist for and seeing what the pharmacist can bring back to the doctor."

Resident (at week 2): "Something that I see is [the pharmacist]'s interaction with the medical staff, primarily the staff nephrologists and somewhat of the fellows. I have always known that I could be respected as a pharmacist but I think she sees herself and they see her as a peer; and that to me is probably the thing that I've learned the most or gives me encouragement but also something to strive for."

In particular, this strategy allowed more opportunities for the junior students to observe the senior students interacting with the medical team.

In terms of the level of comfort that physicians had with the number of pharmacy students on the unit, all physicians expressed their appreciation for the students' contribution:

Attending physician: "I think it's advantageous having them because obviously you can see more people that way. I do think it has been helpful to hear their opinions when we go for rounds."

These observations suggest that employing such a teaching model within a setting centred on interprofessional teamwork gives the junior students a chance to become more familiar with the interactions that occur among the pharmacist, senior pharmacy students, and medical staff. Moreover, the involvement of multiple pharmacy students in this patient care setting appeared to be well received by the medical team.

\section{DISCUSSION AND CONCLUSIONS}

Near-peer teaching provided a unique approach to learning in many respects for the pharmacy students observed in this hemodialysis setting.

There were some limitations worth noting. For each of the 4 types of student, only one individual was observed in this model. Given differences in personalities, levels of motivation, and extent of experience, these findings might not be applicable to a different set of pharmacy students. The unit where this teaching model was implemented is highly specialized, and it is possible that the patient population made this teaching approach particularly feasible in this setting. Whether this approach would be practical in other settings, such as general medicine, is unknown. Observations were carried out only for a 3-week period, and learning outcomes were not examined. Having an observer on site might have led participants to feel compelled to act or respond to interview questions with caution. However, it appeared that the observer was soon regarded as a fellow colleague, rather than as an observer.
Overall, this paper has provided a descriptive account of the complexity of the near-peer teaching model in pharmacy education. Given the increasing demand for high-quality experiential placements, this teaching model offers a unique approach to meeting this need.

\section{References}

1. Position statement and joint resolution on the Doctor of Pharmacy (PharmD) for the first professional degree at universities in Canada. Association of Faculties of Pharmacy of Canada and Associations of Deans of Pharmacy of Canada; 2010 Feb [cited 2012 Jan 29]. Available from: www.afpc.info/downloads/1/AFPC_ADPC_PharmD_Position_ Statement_Resolution_Sept_2010.pdf

2. Bulte C, Betts A, Garner K, Durning S. Student teaching: views of student near-peer teachers and learners. Med Teach 2007;29(6):583-590.

3. Durning SJ, ten Cate O. Peer teaching in medical education. Med Teach 2007:29(6):523-524.

4. Field M, Burke JM, McAllister D, Lloyd DM. Peer-assisted learning: a novel approach to clinical skills learning for medical students. Med Educ 2007;41(4):411-418.

5. Lindblad AJ, Howorko JM, Cashin RP, Ehlers CJ, Cox CE. Development and evaluation of a student pharmacist clinical teaching unit utilizing peer-assisted learning. Can J Hosp Pharm 2011;64(6):446-450.

6. Santee J, Garavalia L. Peer tutoring programs in health professions schools. Am J Pharm Educ 2006;70(3):70.

7. Secomb J. A systematic review of peer teaching and learning in clinical education. J Clin Nurs 2008;17(6):703-716.

8. Cisneros RM, Salisbury-Glennon JD, Anderson-Harper HM. Status of problem-based learning research in pharmacy education: a call for future research. Am J Pharm Educ 2002;66:19-26.

9. Leung WC. Why is evidence from ethnographic and discourse research needed in medical education: the case of problem-based learning. Med Teach 2002;24(2):169-172.

10. Atkinson P, Pugsley L. Making sense of ethnography and medical education. Med Educ 2005;39(2):228-234.

11. Goodson L, Vassar M. An overview of ethnography in healthcare and medical education research. J Educ Eval Health Prof 2011;8:4.

12. Walton JM, Steinert Y. Patterns of interaction during rounds: implications for work-based learning. Med Educ 2010;44(6):550-558.

13. Lempp H, Seale C. The hidden curriculum in undergraduate medical education: qualitative study of medical students' perceptions of teaching. BMJ 2004;329(7469):770-773.

14. Lockspeiser TM, O'Sullivan P, Teherani A, Muller J. Understanding the experience of being taught by peers: the value of social and cognitive congruence. Adv Health Sci Educ Theory Pract 2008;13(3):361-372.

15. Spouse J. Learning to nurse through legitimate peripheral participation. Nurse Educ Today 1998;18(5):345-351.

16. Ward C, Bochner S, Furnham A. The psychology of culture shock. 2nd ed. Philadelphia (PA): Routledge; 2001.

Christine Leong, BSCPhm, is a PharmD candidate in the Leslie Dan Faculty of Pharmacy, University of Toronto, Toronto, Ontario.

Marisa Battistella, BScPhm, PharmD, is a Clinical Pharmacist with the Hemodialysis Unit of the Toronto General Hospital, University Health Network, and a Pharmacy Clinician Scientist and Assistant Professor with the Leslie Dan Faculty of Pharmacy, University of Toronto, Toronto, Ontario.

Zubin Austin, BScPhm, MBA, MIS, PhD, is Associate Professor and OCP Research Professor in Pharmacy with the Leslie Dan Faculty of Pharmacy, University of Toronto, Toronto, Ontario.

\section{Address correspondence to:}

Dr Zubin Austin

Leslie Dan Faculty of Pharmacy

University of Toronto

144 College Street

Toronto ON M5S 3M2

e-mail: zubin.austin@utoronto.ca 